\title{
Inhalt
}

\section{Georg Schmidt}

Zur Einführung $\ldots \ldots \ldots \ldots \ldots \ldots \ldots \ldots \ldots \ldots \ldots \ldots \ldots \ldots \ldots \ldots \ldots \ldots$

Verzeichnis der Tagungsteilnehmer $\ldots \ldots \ldots \ldots \ldots \ldots \ldots \ldots$ XIII

I. Binnensichten

\section{Alfred Kobler}

Österreich und die deutsche Nation - politische und kulturelle

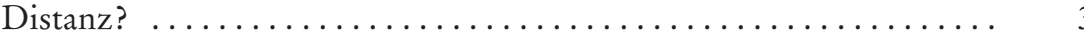

Peter H. Wilson

Imperial Defence. Integration Through Military Cooperation? . . . . .

Alexander Schmidt

Ein Vaterland ohne Patrioten? Die Krise des Reichspatriotismus im

18. Jahrhundert . . . . . . . . . . . . . . . . . . . . . . . . . .

Dieter Langewiesche

Föderative Nation, kulturelle Identität und politische Ordnung.

(Rück-)Blick aus dem 19. Jahrhundert .

II. Die deutsche Nation von außen

Michael North

Nationale und kulturelle Selbstverortung in der Diaspora:

Die Deutschen in den russischen Ostseeprovinzen des

18. Jahrhunderts

Thomas Maissen

Die Eidgenossen und die deutsche Nation in der Frühen Neuzeit ....

Hans-Jürgen Bömelburg

Polen und die deutsche Nation - Konfligierende Identitäts-

zuschreibungen und antagonistische Entwürfe politischer Ordnung . . 
Martin Wrede

Frankreich, das Reich und die deutsche Nation im 17. und 18. Jahrhundert - Wahrnehmungsmuster und Wahrnehmungswandel .......

III. Distinkt oder übergreifend?

Horst Carl

Europäische Adelsgesellschaft und deutsche Nation in der

Frühen Neuzeit

Joachim Whaley

Kulturelle Toleranz - die deutsche Nation im europäischen Vergleich

Siegrid Westphal

Frauenzimmerlexika der Frühen Neuzeit als nationaler

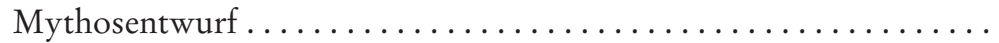

Luise Schorn-Schütte

Politica christiana: eine konfessionelle oder christliche Grundordnung für die deutsche Nation? ...........................

IV. Nationalkulturelle Zuschreibungen

Daniel Fulda

Zwischen Gelehrten- und Kulturnationalismus. Die „deutsche

Nation" in der literaturpolitischen Publizistik Johann Christoph

Gottscheds .....................................

Klaus Pietschmann

Nationale Identitätskonstruktion im deutschsprachigen Musiktheater

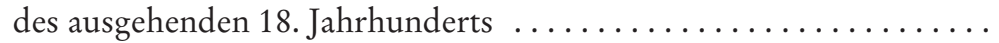

Meinrad von Engelberg

„Deutscher Barock“ oder „Barock in Deutschland“ - Nur ein Streit um Worte?......................................

Astrid Ackermann

Tagungsprotokoll 